\title{
ÁTICO E KOINÉ \\ Problemas na abordagem sociolingüística de uma área dialetal do grego antigo
}

Jorge Ferro Piqué

egundo uma teoria tradicional nos estudos clássicos, os povos gregos penetraram na Grécia vindos do Norte, em levas sucessivas de tribos, como consequiência do movimento migratório dos indo-europeus, por toda a Europa e Ásia.

Essas tribos subjugaram a população autóctone, de etnia "asiânica", e, por sua vez, foram empurradas por novas ondas de gregos para outros lugares.

Observa-se na Grécia, principalmente através de fontes epigráficas, uma multiplicidade de dialetos locais, que através de critérios estruturais podem ser articulados em vários grupos dialetais, claramente distintos entre si, apesar de geograficamente estarem algumas vezes separados; ou porque um território originalmente coerente foi rompido em várias partes por outros dialetos que nele

* Universidade Federal do Paraná. (jorge@coruja.humanas.ufpr.br)

I Mais recentemente o chamado "modelo das ondas" tem sido criticado e substituído pelo modelo da expansão populacional (Cf. RENFREW. C. Arquelogia y Lenguage. Barcelona: Editorial Critica.1990. p. 110-111). No entanto, essa discussão nåo afeta os problemas tratados neste artigo. 
se encrustaram, ou porque um dialeto particular foi levado de sua pátria por emigração ou colonização.

O quadro dialetal geral comumente aceito se constitui de quatro grandes grupos dialetais:

1- O jônico-ático, subdividido nos dialetos jônico e ático;

2- O eólico, subdividido nos dialetos eólio da Ásia Menor (inclusive o lesbiense), tessálio e beócio;

3- O grego ocidental, subdividido nos dialetos dórico e grego do noroeste,

4- O arcádio-cipriota, subdividido nos dialetos micênico, arcádio e cipriota.

Como dissemos antes, o critério deste agrupamento é o de semelhanças estruturais entre dialetos locais, constituindo então um dialeto regional, e entre esses dialetos constituindo-se grandes grupos dialetais.

Este critério, o estrutural, para demarcar fronteiras entre linguas ou dialetos, é o que tradicionalmente foi utilizado nos estudos dialetológicos e se baseia em semelhanças estruturais entre os niveis da língua, isto é, o fonológico, o morfológico, o sintático, o semântico e o lexical, e que em geral correspondem com a posição geográfica. No entanto, mesmo esses critérios puramente estruturais não são de simples aplicação, uma vez que pode ocorrer que aproximações no nível fonológico contradigam os afastamentos no nivel semântico, por exemplo, e do mesmo modo em relação a outros níveis, isto é, não existe necessariamente uma coerência entre os diversos níveis quanto às fronteiras dialetais, o que muitas vezes torna problemática a estabilização da própria categoria dialeto.

O nível da lingua que mais tem sido utilizado nesta comparação estrutural do grego antigo é o fonológico. Assim, apenas para exemplificar, o grupo dialetal grego ocidental, que apresenta um caráter fortemente conservador, mantém a primitiva vogal indo-européia $a$, enquanto que o jônico-ático a substituiu por $e$, desta forma temos dór. /phama/ (expressão, linguagem) ${ }^{2}$ corres-pondente ao jônico-ático/pheme/. Por sua vez, dentro do grupo dialetal jônico-ático, o ático se diferencia do jônico, por exemplo, por esta assimilação: jôn. rs< át. rr.

$\mathrm{Na}$ lingüística atual encontramos comumente os termos "lingua" e "dialeto" usados de forma ambigua. O uso desses termos nos impõe uma divisão em algo que geralmente se apresenta como um contínuo. Seria interessante nos determos um pouco sobre a origem destes dois termos um tanto confusos. 
Segundo Haugen, the linguistic situation in ancient Greece was both the model and the stimulus for the use the terms (isto é, lingua e dialeto) in modern writing. ${ }^{3}$

Pois bem. como vimos, não havia no periodo clássico uma norma unificada do grego, mas sim, apenas um conjunto de normas estreitamente relacionadas.

$\mathrm{Hall}^{4}$ nos informa que tem havido poucas exceções à existência de um padrão lingüístico estandardizado e em geral elas são encontradas em situações artificiais, envolvendo particularmente gêneros literários, e nos cita os exemplos da poesia lírica em velho provençal, do drama em médio hindi e da literatura em grego antigo.

Realmente, enquanto esses "dialetos" gregos, carregam o nome de várias regiões gregas (Jônia, Ática, Eólia, Beócia, etc...), eles não são variedades faladas, mas sim escritas do grego. Cada uma especializada para certos tipos de produção literária. O jônico, por exemplo, para a poesia épica e para a história. o ático para os diálogos nas tragédias, o dórico para as partes cantadas pelo coro nessas mesmas tragédias, e assim por diante. Dessa forma, neste periodo, isto é. o periodo clássico (séc. V a.C. - IV a.C.), a língua que hoje chamamos "grego" era um grupo de distintas, mas relacionadas, normas escritas. conhecidas como "dialetos" (dialektoi).

No periodo pós-clássico ou helenistico a partir do séc. III a.C.. ocorrem tanto mudanças históricas quanto lingüisticas. Robins assim as resume: as conquistas de Alexandre, que colocaram toda a Asia Menor. o Egito e também o solo pátrio da Grécia sob controle macedónio, modificaram o mundo egeu irreversive/mente. Ainda que seu império tenha sido dividido entre seus sucessores (...) a administração e o pensamento grego se difiundiram pela área ocidental do mediterrâneo e pela Ásia Menor; uma variedade do dialeto ático conhecida como Koiné (diálektos), ou dialeto comum, convertert-se em lingua oficial do governo, do comércio e do ensino em toda a região, substituindo gradualmente os antigos dialetos locais ${ }^{5}$ e assim, tornando-se uma lingua comum estandardizada. Este é o panorama histórico-lingüístico geralmente apresentado.

Como já observamos, essa visão dos dialetos gregos parte sobretudo de critérios estruturais.

3 IIAUGEN, LE. Dialed. Ianguage. Nation. In: American Anthropologist. v. 68. n.4 August. 1968 . p. 923.

4 IIALL Jr.. R.A. Piơgins and Creoles as Standard Languages. In: PRIDE. J.B.: HOLMES. J. (ed.) Sociolingnistcs. Selected Readings. Penguin l:ducation. 1976. p. If4.

5 ROBINS. R.H. Pequena História da lingiaistica. Rio de Janeiro: Ao L ivro Técnico SA/I.N.I..1979. p. 12-13. 
Mas é possível também utilizarem-se, para certos tipos de variação lingüística, critérios ditos não-estruturais. Pride nos cita alguns deles: observações sociolingüisticas de desempenho; avaliação de inteligibilidade mútua ou não-recíproca; crenças dos usuários da lingua; considerações políticas ou outras considerações institucionais; atitudes; relações históricas ou diacrônicas; etc...

Mas assim como os critérios estruturais, estes também não são de fácil aplicação, pois em casos particulares são verificadas complexas incompatibilidades entre eles, e para as quais não existe provavelmente nenhuma chave única ou simples. Essas situações indicam que os sistemas lingüisticos são muito mais complexos e que incluem mais do que relações puramente estruturais.

López Eire, helenista espanhol, parte exatamente desse fato ao reclamar que ao lado das dimensões espacial e temporal em que tradicionalmente são analisadas as variações do grego, no âmbito da fillologia clássica, seria necessário acrescentar a dimensão vertical, já que a língua é um fenômeno eminentemente social e relacionada a sua estrutura global. ${ }^{7}$ Apóia sua tese nos estudos de Labov, que, segundo L. Eire, teria correlacionado certos traços dialetais do inglês falado em Nova York, com precisos níveis sócio-econômicos. ${ }^{8}$

Neste artigo procuraremos examinar como o referido autor aplicou critérios sociolingüisticos à área dialetal do grego antigo, mais especificamente como correlacionou esses critérios à mudança lingüistica que ocorreu na passagem do dialeto ático do séc. $V$ a.C. ao dialeto comum (koiné) do séc. III a.C. e que tipos de problemas são inerentes a tentativas desse tipo.

Quanto aos critérios sociolingüisticos que lhe pareceram os apropriados, cita os de três autores: Ferguson (atitudes de índole política ou institucional). Wolff (a inteligibilidade mútua) e Fishman (os fatores observáveis, isto é, quem, onde, quando, etc...). No entanto, parece apoiar-se mais neste último e por esse motivo vejamos um breve resumo de sua teoria.

Fishman é um sociolingüista conhecido principalmente por seu importante estudo sobre os padrões de bilingüismo (espanhol/inglês) numa seção da população porto-riquenha na cidade de Nova York.?

6 PRIDE. J.B. Sociolingüistica. In: LYONS. J. (org.). Novos Horizontes e'm Lingï̈istica. São Paulo: Cultrix/EDUSP. 1976. p. 280-1.

7 LÓPEZ EIRI: A. Del Ático a la Koiné. In: Emerita. 1981. Tomo XI.IX, lasc. $2^{\circ}$. p. 180.

8 Note-se que Pride, referindo-se a Labov, atenua essa afirmaçào, colocando que nesses estudos nem sempre é possivel relacionar certos aspectos da linguagem utilizada com as medidas de estratificação sócio-cconômica, pois estão também estatisticamente relacionadas com outros latores como o grau de mobilidade social e com o nivel de atençào e/ou despreocupaçăo cm cada interação especifica (Cf. PRIDE. J.B. Sociolinguistica. In: LYONS. J. (org.). Novos /lorizontes em Lingïistica. Sào Paulo: . Cultrix/EDUSP. 1976. p. 279).

a FISHMAN. J.A. Bilinguisin in the Barrio. 1968. 
Nesse trabalho Fishman faz uma escolha decisiva sobre a constituição de seu campo de estudo. A demarcação de dialetos, variedades e estilos de linguagem, através de outros fatores além dos puramente estruturais é mais dificil que investigar diferentes espécies do que em geral se chama "comutação de código" (code-switching), no qual as alternativas sejam linguas indubitavelmente distintas. Nesse caso, pode-se estar mais razoavelmente seguro daquilo que está sendo comutado do que no caso dos dialetos. Acrescente-se a isso que a observação é feita diretamente nos niveis de face-lo-face encounters.

É esperado, no entanto, que a opção por descrever a escolha de linguagem em ambientes multilinguais estáveis, nos quais os membros dos grupos utilizam mais de uma lingua para comunicar-se entre si, possa talvez mais tarde ter seus resultados utilizados para descrever situações mais complexas de escolha lingüistica.

Temos assim um exemplo característico dessa situação em um funcionário público hipotético de Bruxelas que fala geralmente o francês como padrão em seu escritório, o holandês padrão no clube e uma variante local particular do flamengo em casa: mas há ocasiỏes em que no clube ele pode falar francês, no escritório falar alguma variedade de flamengo, ou falar o holandês ou o francês em casa.

Diante de quadros como o descrito acima, e que são muito mais comuns do que se imagina, Fishman coloca: Thus, our overall problem is wofold: (I) to recognize and describe whatever higher-order regularitics there ma be choosing among the several varieties that constitute the repertoire of a multilingual speech comunity and (2) nevertheless to provide the interpersonal fluctuation (lower-order societal patterning) that remains even when higherorder societal patterning is establisched. ${ }^{10}$

A seguir procura elaborar categorias sociolingüisticas através de certos parâmetros que permitam alcançar tanto uma acuidade factual como consistência teórica e que esclareçam as relações entre os falantes e os diversos tipos de linguagem escolhidos.

Para começar, nota-se no caso belga que dependendo do assunto tratado na conversação se escolhe uma ou outra lingua, francês para assuntos gerais ou econômicos, por exemplo.

Como observa que certas escolhas entre várias linguas ou mesmo vascilações de emprego, estão relacionadas com o conteúdo dos enunciados, que

10 FISIIMAN, J.A. The Relationship between Micro- and Macro-Sociolinguistics in the Study of Who Speaks What Language to Whom and When. In: PRIDF.. J.B.: HOIMES. J. (cd). Sociolinguistcs. Selected Readings. Penguin Education, 1976. p. 17.

" Essas categorias serào os "tópicos". os "dominios" e as "relaççes de papéis". 
chama "tópicos", estes são considerados com um dos reguladores do uso lingüístico em ambientes multilinguais.

Ao que parece, por algum motivo que não se sabe, certos assuntos para o falante parecem ser melhor transmitidos numa língua que noutra. Mas além disso, pode haver outros fatores que reforcem essa relação como o hábito, o treinamento, ou uma necessidade de usar certos termos especializados que apenas uma língua desenvolveu suficientemente no seu vocabulário, e assim de outras maneiras.

Justamente devido à multiplicidade de causas que podem estar sob a regulação tópica do code-switching, é que Fishman não a considera como uma variável analitica e descritiva conveniente em sociedades multilinguais como principal suporte teórico.

Para ele certas reconhecidas esferas da atividade sócio-cultural estariam por trás da oscilação entre as línguas no seu uso pelo falante, e que poderiam também explicar porque certos tópicos estão mais ligados a certas línguas que outros.

Schimidt-Rohr, em 1932, parece ter sido o primeiro a sugerir que dominance configurations precisariam ser estabelecidas para expor o status global em vários domínios de comportamento e distingue assim nove domínios: a familia, o pátio de recreio e a rua, a escola, a igreja, a literatura, a imprensa, as instituições militares, as cortes e a administração governamental.

Fishman retoma essa categoria que também havia sido desenvolvida em estudos sobre aculturação, relações intergrupais e bilingüismo: domain (of language behovior) is a social-cultural construct abstracted from topics of communications, relationships between comunicators, and locales of communications, in accord with the institutions of a socialy and the spheres of activity of a speech community, in such a way that individual behavior and social patterns can be distinguished from each others and yet related to each others.

Em uma nota, Fishman põe-se claramente contra a idéia algumas vezes encontrada em discussões sobre dominios, de que haveria um conjunto invariável destes e que seriam sempre aplicados todos a ambientes multilinguais, pois se o comportamento lingüístico se relaciona diretamente com padrões sócio-culturais, será evidente que uma comunidade particular de fala multilingual deve primeiramente sofrer uma análise profunda da sua dinâmica sóciocultural em um periodo particular de sua história para se definir que recorte de domínios seria mais proveitoso para a descrição sociolingüistica.

Dentro dos domínios encontra-se por sua vez diferenciações entre locutores. Assim, em certas sociedades, comportamentos particulares (incluindo comportamentos lingüísticos) são esperados de indivíduos particulares frente a frente a outros e poderíamos construir diades de papéis sociais (mãe-filho, 
professor-aluno, etc...) correlacionados dentro dos dominios a diferentes escoThas lingüisticas, que Fishman chama de "relações de papéis" (role-relations). Isto por sua vez não significa que toda possivel diferença de "relações de papéis" está necessariamente relacionada a diferenças na escolha lingüística. Portanto. as role-relations, tanto quanto os dominios, devem ser empiricamente determinadas para cada comunidade multilingual em um tempo preciso.

Apenas acrescentemos que a certos domínios numa sociedade especifica estão relacionados "locais" determinados, por exemplo, o dominio escolar no prédio da escola.

Assim Fishman sustenta que fatores como prestígio, sentimentos de lealdade lingüistica, relações interpessoais vinculadas a poder e intimidade e outros não podem ser empiricamente aferidos com facilidade e tendem a significar coisas diferentes em ambientes diferentes. Podemos então resumir da seguinte maneira suas idéias sob a forma de três decisões teóricas:

1. Colocar o conceito de "domínio" na vanguarda da análise.

2. Resolver os domínios primordialmente em "relações de papéis"constituintes.

3. Pesquisar correlações entre estas duas categorias e a escolha da linguagem.

O objetivo desta análise seria então ater-se apenas ao que Pride chama de "fatores observáveis", isto é, quem fala qual língua, sobre qual conteúdo, onde e quando.

Fishman finalmente reúne o que se chamaria de "fatores não-observáveis", sob a atividade de dois conjuntos complementares de domínios, que corresponderiam a dois "grupos de valores" para a sociedade dada. Seriam eles, a "alta cultura", que daria ênfase ao mútuo distanciamento interpessoal, relações de poder, formalismo e ritual, e que abarcariam domínios como a escola, a administração governamental, a literatura, etc..., e a "baixa cultura", onde ao contrário se situariam as manifestações de espontaneidade, camaradagem, intimidade, comunhão étnica e que por sua vez abarcaria domínios como a família, a vizinhança, etc...

Pois bem, este é o arcabouço teórico tranquilamente aceito por López Eire. Vejamos agora como ele o aplica ao seu problema especifico, isto é, como se deu a evolução do dialeto ático falado em Atenas no período clássico até a koiné, língua comum ou franca no periodo helenístico.

$\dot{E}$ exatamente desse aspecto supletório da teoria de Fishman, a oposição high culture vs. low culture, que López Eire parte: Efectivamente, en qualquer lengua hay un nivel alto y otro bajo, e acrescenta, no suele faltar un nivel intermedio de compromiso entre ambos.

Distribui e qualifica, a seguir, estes três niveis quanto à lingua grega: 


\section{Nivel alto:}

- normalmente ligado à escrita;

- submetido a regras estritas;

- não se identifica com o dialeto local;

- propício ao conservadorismo;

- próprio das camadas sociais altas.

Estaria representado na linguagem das inscrições ("lingua oficial") ou pela linguagem da literatura.

2. Nivel baixo:

- não está representado normalmente pela escrita;

- não está regido por regras estritas;

- costuma coincidir com o dialeto local;

- é propício à inovação;

- caracteriza as camadas sociais baixas.

Encontrar-se-ia na linguagem das inscrições em vasos, em determinados "erros" que aparecem na língua oficial das inscrições e em certas palavras, frases feitas ou refrões que se encontram na comédia.

3. Nivel de compromisso ou intermediário:

- é a língua conversacional, coloquial, usual ou corrente.

Encontrar-se-ia nos diálogos das comédias de Aristófanes em sua versão de linguagem de cidadão médio, ou nos diálogos de Platão, no seu aspecto mais cultivado.

Assim, implicitamente, López Eire relaciona alguns "domínios" com niveis. O nivel alto se encontraria nos domínios da administração governamental e da literatura, sendo que os niveis intermediário e baixo seriam apenas perceptiveis por certos desvios encontrados no domínio da literatura e no que poderiamos chamar de "domínio da cerâmica".

Pode-se comparar o caráter enormemente conservador do nivel alto em relação ao conversacional pelo seguinte exemplo: nos documentos redigidos em ático até o ano de 420 a.C. permanecem as terminações de dativo plural -asi ou - esi, enquanto que na língua poética já existia desde o séc. VIII a. C. a terminação -ais, que no séc. V a.C. passara a integrar-se no nível do ático conversacional.

Ora, essas aplicações que López Eire faz das categorias sociolingüisticas de Fishman ao quadro do grego antigo revelam algumas inadequações.

Primeiramente, Fishman trabalha sobre o code-switching entre duas linguas bem diferentes, espanhol e inglês, propositalmente para permitir uma análise mais fácil, enquanto López Eire correlaciona certas escolhas lingüisticas com domínios e níveis culturais dentro de um único dialeto, o ático, o que traz uma dificuldade maior na análise. 
No entanto, mais importante que isso, é uma diferença quanto aos dados sobre os quais se efetuam as duas análises sociolingüisticas. Fishman usa o método da observação, tanto sobre as comunicações orais em situações de face-lo-face encounters, quanto sobre o contexto extralingüístico em que estas ocorrem, isto é, quem, onde, quando, etc...

Já López Eire, e todos aqueles que estudam as chamadas "linguas mortas", só possuem a sua disposição as fontes escritas, que são as inscrições epigráficas, os manuscritos e papiros que foram copiados através dos séculos.

É normalmente assumido que os dialetos escritos eram em última análise baseados em dialetos falados nas regiões que levam seus nomes. Entretanto é extremamente dificil precisar o que seria a língua efetivamente usada pelo falante. Em algumas obras literárias, a língua escrita imita a oral, mas segıındo as suas necessidades intrinsicas, isto é, como emissor e receptor não estão face a face, a escrita não permite. por exemplo, que o receptor interrompa a emissão para esclarecimentos, o que jả alterará profundamente a sua capacidade de imitação. ${ }^{12}$

Assim possuimos apenas para nossa observação a parte escrita do dominio governamental, isto é, as leis, os decretos que foram inscritos na pedra e aquilo que sobrou através dos séculos do dominio literário, excetuando-se claro tudo que fosse apenas oral nesse domínio. Em suma, muito pouco.

Mesmo que a hipótese de L. Eire esteja correta, isto é, se a lingua escrita transmitir o chamado "nível cultural alto", seria extremamente problemático identificar nela indícios dos outros niveis, pois o simples fato de que ocorre certa variação dentro de um padrão escrito não significa necessariamente que possa ser correlacionada a domínios e níveis culturais, para isso teriamos que possuir dados que de fato não dispomos.

$\mathrm{Na}$ falta destes, Lópes Eire pretende que as diferenças nos textos reflitam a oposição inovação $x$ conservadorismo. Como aceita a tese de que o conservadorismo é uma caracteristica do nível social alto, aquela oposição atua como um divisor de águas entre os dois niveis, que por sua vez refletiriam uma oposição entre nível social alto e baixo, que, por sinal, não parece estar baseada em uma análise mais profunda da sociedade grega no séc. $V$ a.C., e necessária sempre que se trabalha em sociolingüística, mas sim apenas em um vago senso comum.

12 Goody c Watt nos falam de uma certa "tensão" entre a transmissđon cultural oral ce escrita ( CT. GOODY. J.: WATT. A. The Consequences of Literacy. In: GIGLIOL.I. P.P. (ed.) Language and Social Context. Selected Readings. Penguim Books. 1982. p. 341, 344-5. 353). 
Assim, substituindo dados mais palpáveis, López Eire se apóia na hipótese que a linguagem do nivel cultural mais alto seria mais conservadora. Voltaremos a esse ponto mais adiante.

Como já foi dito, a análise de L. Eire tem como objetivo relacionar o ático do séc. $V$ a.C. e a koiné do periodo helenístico através de variáveis sociolingüísticas.

Para isso é introduzido um novo critério não-estrutural além do critério dos fatores observáveis no desempenho lingüístico e das identificações culturais (nivel alto versus nível baixo). São as considerações políticas no nível macrosocial. Vejamos então alguns dados históricos sobre a Grécia do séc. V a. C.

Xerxes, soberano persa, em 480 a.C., lançou uma terrivel campanha contra a Grécia, derrotando e submetendo inúmeras cidades gregas na Ásia Menor e no continente, como parte da expansão do império persa que sucedeu a sua unificação sob o reinado de Ciro, seu bisavô.

Em 478 a.C. funda-se a Liga ático-délica. Tratava-se de uma aliança maritima entre várias cidades, principalmente jônicas (isto é, na costa da Ásia Menor), além de ilhas e Atenas. Seu objetivo era a defesa contra novos ataques persas, mas sob esse propósito aparente ocultava-se outro.

O centro da Liga era a ilha de Delos, mas logo foi substituida por Atenas, que passou a obrigar seus aliados a servirem no exército ateniense, a vir a Atenas para submeterem-se a determinados processos judiciais, enquanto estes, por sua vez, recebiam guarnições atenienses, assim como funcionários estatais encarregados de realizar inspeções e cidadãos pobres de Atenas que, sem perder a cidadania ateniense, cultivassem lotes de terra.

Através dessas medidas Atenas assenta sua hegemonia sobre as demais cidades, passa a ser a capital de um império e o centro cultural mais importante da Grécia. Enquanto para uso interno desfrutava de uma constituição democrática, guiada pela política imperialista de Péricles, impôs seu domínio sobre as demais cidades, utilizando da ameaça persa como pretexto. No entanto a hegemonia ateniense não podia sustentar-se apenas sobre a força militar e o controle central do sistema juridico, necessitava também da unidade ideológica dos gregos, baseada na comunidade de religião, tradições, costumes e língua. Necesitaba, además, una lengua cuyo uso no se limitase al espacio aharcado por los muros de la ciudad de Alenea o los confines del Ática. Tenia necesidad de una lengua que cumpliese su función en un nuevo espacio geográfico, mucho mas amplio, que se ajustase a las nuevas funciones administrativas, diplomáticas, comerciáles y militares, que sirviese como lengua de tráfico (Verkersprache) apta para una potencia que dominaba el mar Egeo y se extendia sobre Tracia, ciudades de Asia Menor y el Ponto Euxinto. Atenas, en suma, como capital de un gran imperio, requeria todo lo contrario a un vehiculo de 
expresión provinciano, regional o local: le era menester una lengtua supradialectal que pudiera ser empleada por los atenienses y los aliados de la Liga o stibditos del imperio. ${ }^{13}$

Este assim chamado "ático imperial" seria a nova lingua conversacional que surge em Atenas no séc. $V$ a.C. e que nasce como nivel de compromisso entre a "língua de baixo nivel cultural", o ático puro e castiço, e a "língua de alto nivel cultural", a língua literária.

Observa-se a partir desse momento certas modificações na lingua das inscrições oficiais, isto é, os decretos, que antes eram escritos em ático antigo, modificações estas que mais tarde terão enorme emprego na Koiné, como o aparecimento das terminações de dativo plural/-ais/.

Para compreendermos como essa lingua se constituiu não podemos esquecer que Atenas está à frente de uma liga que é fundamentalmente jônica. o que estimula que a nova lingua ática do império procure eliminar seus traços lingüisticos exclusivos, para nivelar seu falar ao máximo com o de seus súditos, de cujo concurso, afinal, Atenas precisava.

Por outro lado, quando se tenta constituir uma lingua nacional. costuma acontecer que o seu domínio literário, integrante do nivel de alta cultura, influa fortemente na sua formação, como nos casos da Alemanha e da Itália, por exemplo. Nesse domínio, o dialeto jônico tinha um lugar importante, pois além de ser a lingua de Homero e Hesiodo na poesia, foi nesse dialeto que se transmitiu em prosa conhecimentos históricos, científicos e filosóficos. Por isso era comum encontrar-se nas tragédias palavras jônicas, formas de prestigio frente as usuais em ático. Ferguson também observou esse fenômeno em árabe, grego moderno, alemão suiço e haitiano creolo: in every one of the defining lenguages there is rizable body of written literature in $H$ (isto é, "high variety") which is held in high esteem by the speech community. o que provoca em certas situações coloquiais uma mistura. com o uso por exemplo de um vocabulário clássico. com certos traços sintáticos clássicos, mas com uma base fundamentalmente coloquial na sintaxe e na morfologia.

Além disso, no ano de 403 a.C. é adotado em Atenas o uso do alfabeto jônico, isto é, se acepta y reconoce el instrumiento mas importante de una lengua en su "nivel de alta cultura". 14 a lingua escrita.

Podemos caracterizar assim por três traços essenciais o ático imperial:

1. um componente básico que é fundamentalmente ático;

2. um componente jônico que se superpõe sobre o anterior, modificando-o ;

13 I.ÓPEZ EIRE. Del Ático a la Koiné. In: Emerita. 198I. tomo XI.IX. fasc. 20. p.200.

14 Ihid. 
3. um fator de regularização, em virtude do qual se elimina tudo de idiomático que possuía o dialeto base sobre o qual se desenvolveu.

Este novo ático que surge no séc. $V$ a.C. é o embrião da lingua standard que surgirá no periodo helenístico (séc. III a.C.) em que um novo e verdadeiro império, o macedônio, se estabelecerá e sobre uma região muito maior.

Assim, a koiné mantém os traços que o jônico e $o$ ático tinham em comum. Quando ocorre discrepância entre esses dois dialetos, a escolha recai sobre soluções consagradas pelo prestigio literário e o uso mais generalizado. evitando-se as formas exclusivamente áticas. Quando mantém ainda traços áticos é porque gozam de prestigio cultural por serem utilizados na língua literária empregada nos diálogos da tragédia e nos começos da prosa ática.

Tentaremos resumir agora e colocar de uma forma mais explícita do que López Eire o fez em seu artigo os conceitos de Fishman aplicados ao grego antigo.

Dentro da norma ática, os dominios melhor representados são os que integram o nível de "alta cultura". Seriam no mínimo dois:

a) domínio jurídico: encontrado nos decretos e leis inscritos na pedra. caracterizado por um ático puro e extremamente conservador.

b) domínio literário: encontrado nas obras em prosa e nas tragédias representadas em Atenas. Tem como base o ático, mas sofre a influência do dominio literário da norma jônica, por ser o dialeto de maior prestígio e tradição escrita.

Tanto os niveis de "baixa cultura", como o "intermediário", por terem acesso restrito à escrita, seriam menos delineáveis. O nível de "compromisso" seria o ático conversacional, que talvez pudesse ser atribuído ao domínio da rua ou da vizinhança, ou a outros dominios em que encontrássemos a relação de papéis do tipo cidadão-cidadão. Seria caracterizado tanto por formas antigas como por novas.

Uma modificação no nivel mais amplo da sociedade, isto é, as necessidades ideológicas de uma politica expansionista, repercutirá primeiramente no nível conversacional, onde serão excluídas as formas mais tipicamente áticas e serão incluidas formas jônicas e de prestígio literário e acabarão por se fazer sentir também o domínio jurídico, conforme o Quadro 1.

15 Ferguson chama este fenòmeno de Koineization. no qual dialects are homogenized hy the modification or elimination of features wich are felt to be especially' distinctive of a particular regional dialect e the dá um caráter geral aplicando-o também a certas variedades de árabe que se tornaram lingua franca (pan-Arabe Koine) (CI. FERGUSON. L.A. The Role of Arabic in Ethiopia: A Sociolinguistics Perspective. In: PRIDE. J.B.; HOLMES, J. (ed) Sociolinguistes. Selected Readings. Penguin Education. 1976. p. 116-7. 
Quadro I

\begin{tabular}{|c|c|c|}
\hline & NORMA ÁTICA & NORMA JÔNICA \\
\hline Nivel alto & $\begin{array}{ll}\text { Domínio } & \text { Domínio } \\
\text { Jurídico } & \text { Literário }\end{array}$ & $\begin{array}{l}\text { Dominio Literário } \\
\text { ???? }\end{array}$ \\
\hline $\begin{array}{l}\text { Nivel } \\
\text { intermediário }\end{array}$ & $\begin{array}{l}\text { Ático } \\
\text { conversacional } \\
\text { P }\end{array}$ & $? ? ? ?$ \\
\hline Nivel Baixo & $\begin{array}{l}\text { Inscriçð̃es } \\
\text { em vasos }\end{array}$ & ???? \\
\hline
\end{tabular}

???? : Falta de dados lingúisticos sobre outros domínios em cada nivel

$\rightarrow$ : Influèncias normais entre os domínios

....... : Influências a partir do imperialismo ateniense (séc. $V$ a.C.)

Finalmente, o uso extensivo dos falantes dessa variedade social do ático, isto é, o "ático imperial", transformaram-na a partir do império de Alexandre, numa nova norma, a Koiné, que se transformará em uma lingua standard para toda a área do Mediterrâneo oriental e Ásia Menor.

Apesar dessa hipótese ser extremamente interessante e sedutora, lembremos que talvez seja prematura em vista da enorme falta de dados de que dispomos, como indicado no quadro. Por exemplo, qual teria sido o papel dos niveis "intermediário" e "baixo" da norma jônica na constituição do "ático imperial"? Não sabemos, mas provavelmente teria havido alguma influência devido ao contato das guarnições atenienses em cidades jônicas. O que também nos leva a perguntar se existiria um "domínio militar", caracterizado por uma escolha lingüistica específica e que teria tido um maior papel dentro do contexto imperialista. Também quanto a esse ponto nos faltam dados.

Por outro lado, a própria teoria de Fishman apresenta alguns problemas na sua aplicação mesmo a ambientes lingüisticos com maior facilidade de observação.

Existem em verdade muitas indicações no seu estudo do bilingüismo espanhol/inglês em Nova York, "de comutação de código" que ocorre contra 
um fundo situacional que absolutamente não muda de modo perceptível como nos afirma Pride. ${ }^{16}$ Talvez esses comportamentos fossem melhor descritos em termos de fatores não-observáveis, que seriam algo como "repreender uma criança versus discutir com ela objetivos e aspirações educacionais, expressão de ira versus advertência de ira eminente, argumentação versus discussão", etc.

Ao que parece esses fatores não-observáveis explicam o comportamento repetido de comutação de código dentro de domínios, relações de papéis e ambientes específicos e, portanto, estes não nos capacitam a descrever ou explicar adequadamente tal comportamento. Conforme Pride, novamente: Uma saida desse impasse poderia ser a de submeter os resultados da investigação de dominio à análise de fatores, na esperança de descobrir correlações mais generalizadas, capazes de lançar alguma luz em tais comportamentos mais problemáticos de comutação de código. ${ }^{17}$ É o que Fishman tentou de certa forma fazer ao estabelecer dois conjuntos complementares de domínios, o primeiro de alta cultura e o segundo de baixa cultura. Mas é duvidoso que a complexidade do conjunto dos fatores não-observáveis possa ser adequadamente decomposta nesses dois niveis, mesmo acrescentando-se um "nível intermediário", como faz López Eire.

É evidente que a determinação do quadro dos fatores observáveis se constitui em exigência a qualquer análise, mas este é um trabalho preliminar para o estudo também dos fatores não-observáveis e não se basta por si só.

Para finalizar faremos um breve resumo do trabalho de Bright sobre a variação sociolingüistica no subcontinente indiano. ${ }^{18}$ Esse trabalho é colocado aqui como contraponto à investigação de López Eire no grego antigo, pois além do enfoque histórico, trabalha com certas categorias muito próximas às tratadas anteriormente.

Segundo Bright, existem diferentes tipos de variação sociolingüistica. Mais freqüentemente essa variação reflete a relação entre o status do falante e o status da pessoa a quem se destina a enunciação. Entretanto outros fatores no contexto social e cultural também podem influir: A type of variation which is familiar in most societies is correlated with the difference between formal and

16 PRIDE. J.B. Sociolinguistica. In: LYONS, J. (org) Novos Horizontes em Lingiüistica. SP: Cultrix/EDUSP. 1976. p.283.

17 Ibid.

18 Na India temos um número muito grande de linguas diferentes. como o kanarese, o tamil. o tulu. etc.. que pertencem à familia das línguas dravidicas. ou como o hindi. o punjabi. etc. que são indo-europćias. 
informal situations - "formality" and "informality" being defined, of course, in terms of particular society (grifo nosso). ${ }^{19}$ Mas se em alguns casos essa oposição se constitui de uma forma particular, in some languages (...) the styles of speeach used in formal vs. informal situation are highly standardized and strictly differentiated. Esse fenômeno se inclui dentro do que Ferguson chamava de "diglossia" e que é observado em árabe, grego moderno, alemão suiço e haitiano creolo, isto é, em suas próprias palavras, one particular kind of standardization where two varieties of a language exist side by side throughout the community, with each having a definite role to play. ${ }^{20}$

O campo indiano é especialmente interessante para a sociolingüistica por reunir diversos tipos de influências sociais sobre a variação lingüistica.

Em primeiro lugar temos uma correlação entre os sistemas de castas indiano e a variação lingüistica, de modo que aos três estilos do kanarese conversacional correspondem às três principais clivagens no sistema de castas: os brâmanes, os não-brâmanes e os Harijans ("intocáveis"). Note-se nesse caso a facilidade que nos é oferecida na delimitação do status social em comparação com os dados gregos, pois na Índia o indivíduo já nasce dentro de uma casta e dela não pode se separar.

Mas além disso, muitas línguas da Ásia do Sul apresentam uma clara diferença entre um estilo formal, geralmente equacionado com a "linguagem literária", e um estilo informal ou coloquial. Assim em kanarese, recobrindo as diferenças dialetais que se correspondem tanto com a casta quanto com a geografia, existe um estilo formal que toda pessoa educada usa em certas situações tais como a leitura, as performances dramáticas e a composição escrita.

Poderíamos abreviadamente expor este quadro em relação à expressão "desculpe-me", que apresentaria as seguintes formas:

FORMAL
/kšamisu/ $\quad$ COLOQUIAL $4\left(\begin{array}{c}\text { BRÂMANE /kšemsu / } \\ \text { X } \\ \text { Não- BRÂMANE /Šensu/ }\end{array}\right.$

Teriamos nesse exemplo, de forma clara, como se combinam dois tipos de variação lingúística socialmente condicionada.

Note-se desde já a diferença entre as investigações de Bright e López Eire. O primeiro tem a sua disposição situações de encontro face a face, num

19 BRIGHT, W. Social dialect and Language History. In: Current Anthropology, v. 1. 1060. p. 424.

20 Ibid. 
campo especialmente escolhido em função das facilidades que oferece à pesquisa.

Ao comparar os dialetos de casta, brâmane e não-brâmane, com o kanarese antigo e o kanarese médio, Bright observa que eles apresentam certas diferenciações, principalmente quanto à perda de vogais mediais. Nesse caso, qual dos dois dialetos teria iniciado as mudanças, ou foram ambos mas de forma independente?

Segundo alguns linguístas (Joos, 1952), ${ }^{21}$ é sugerido que mudanças fonéticas e talvez a mudança lingüistica em geral sejam iniciadas pelas classes altas, in order to maintain a prestige-marking difference das classes baixas, que por sua vez imitando as novas formas da elite tentam diminuir a distância, o que por sua vez forçaria a mais inovações.

Especificamente na língua kanarese, a situação se apresenta da seguinte forma. O dialeto brâmane apresenta mais inovações no que Bright chama de niveis mais conscientes (more conscious level) de mudança lingüística, como os empréstimos de outras línguas e uma maior extensão semântica dos termos, enquanto o dialeto não-brâmane mostra grandes inovações nos tipos de mudanças menos conscientes, isto é, os que envolvem morfemas e fonemas.

Quanto ao tipo de inovação que se apresenta no dialeto brâmane, provavelmente se deva a maior familiaridade dos brâmanes com linguas estrangeiras e sua vida intelectual mais ativa. Menos evidente no entanto é a razão de seu conservadorismo nas mudanças menos conscientes.

A hipótese que Bright sugere é de que a "aptidão literária" (literacy) tenha atuado como um freio nas mudanças desse dialeto. A fonologia e a gramática imobilizadas da língua escrita foram um fator retardador das mudanças.

A situação em outra lingua dravídica, a língua tulu, parece confirmar essa hipótese. Nessa sociedade também existe a distinção dialetal brâmane versus não-brâmane, mas não existe uma literatura tulu, que para isso usa uma segunda língua, kanarese, sânscrito ou inglês. Aqui tanto os dialetos não-brâmane quanto brâmane mostram mudanças fonêmicas em nivel igual.

Assim, Bright formula sua hipótese quanto aos tipos de mudanças lingüiticas e a diferenciação social: although "conscious" linguistic change comes largely from higher social strata, "unconcious" change is natural in all strata where the literacy factor does not intensive. ${ }^{22}$

Zengel, que efetuou um estudo na terminologia legal do latim num periodo de 2000 anos, chega à conclusão também que em áreas onde a literacy

21 BRIGIIT. W; RAMANUJAN, A.K. Sociolinguistic Variation and Language Change. In: PRIDE, J.B. : HOLMES, J. (ed.) Sociolinguistics. Selected Readings. Penguin Education. 1976. p. 158 . 
é uma necessidade primária e integral no processo de comunicação, é possivel ocorrer um retardamento na velocidade da mudança no âmbito do vocabulário da lingua. 23

No entanto, como enfatiza Haugen, a conclusão de que a posse de uma escrita e a existência de uma literatura desenvolvida inibe a mudança lingüistica ainda não foi suficientemente testada, apesar de ser possível citarem-se outros exemplos, como o islandês, onde o grande arcaísmo dessa língua talvez possa ser relacionado a sua antiga tradição literária. ${ }^{24}$

Se aplicássemos essa hipótese ao caso grego, veriamos que o "ático imperial" apresenta, por um lado, um grande número de inovações de nível menos consciente e que mais tarde serão as formas preferidas pela koiné, da qual seria o embrião, e, por outro, preserva as formas literárias jônicas e áticas que gozam de grande prestígio, apresentando uma espécie de compromisso entre as duas normas.

No entanto, para concluir, apesar do estudo de López Eire ter o mérito de ser uma das poucas tentativas de elucidação sociolingüística dos dialetos do grego antigo, nos parece, por isso mesmo, pecar por uma certa prematuridade, visto que, mesmo as teorias desenvolvidas a partir de áreas de estudo as mais favoráveis ainda não estão bem consolidadas ou se mostram mesmo insuficientes. No caso grego, acrescenta-se à debilidade teórica a inadequação da falta de material oral para a observação.

Apesar do exposto acima, nossa posição não é de forma alguma de desesperança, mas sim de cautela. Cremos, de fato, que os estudos das linguas clássicas ainda terão muito a ganhar com os avanços e discussões da sociolingüística e mesmo tentativas incipientes têm sem dúvida a qualidade de ao menos apontar para essa dimensão da linguagem tão relevante quanto qualquer outra.

\section{RESUMO}

Procuramos avaliar os problemas na tentativa do helenista López Eire $\mathrm{em}$ seu artigo Del Ático a la Koine de utilizar categorias tomadas das teorias sociolingüisticas para abordar a passagem do dialeto ático do séc. $\mathrm{V}$ a.C. Koiné helenistica do séc. III a.C.

Palavras-chave: Dialetos gregos, sociolingiuistica, história da lingua grega.

23 ZENGEL, M.S. Literacy as a Factor in Language Change. In: American Anthropologist. vol. 64, $n^{\circ} 1$ February. 1962. p. 139

24 BRIGHT, W. ; RAMANUJAN, A.K. Op. cit. 


\section{ABSTRACT}

We try to evaluate the problems in the López Eire's attempt to utilize sociolinguistic categories to approach the historical change from Attic dialect to Hellenistic koine.

\section{REFERÊNCIAS BIBLIOGRÁFICAS}

BRIGHT, W. Social dialect and Language History. In: Current Anthropology. v. 1. 1960. p. 424-425.

BRIGHT, W. : RAMANJUAN, A.K. Sociolinguistic Variation and Language Change. In: PRIDE,J.B.; HOLMES, J. (ed.) Sociolinguistes. Selected Readings. Penguin Education, 1976. p.157-166.

FERGUSON, L.A. Diglossia. In: Word, v. 15, n. 2. 1959.

The Role of Arabic in Ethiopia: A Sociolinguistic Perspective. In: PRIDE. J.B. ; HOLMES, J. (ed.) Sociolinguistcs. Selected Readings. Penguin Education. 1976. FISHMAN, J.A. The Relationship between Micro- and Macro-sociolinguistics in the Study of Who Speaks What Language to Whom and When. In: PRIDE, J.B.: HOLMES, J. (ed.) Sociolinguistcs. Selected Readings. Penguin Education, 1976. GIGLIOLI, P.P. (ed.). Language and Social Context. Selected Readings. Penguin Books, 1982.

GOODY, J. ; WATT, A. The Consequences of Literacy. In: GIGLIOLI. P.P. (ed.). Language and Social Context. Selected Readings. Penguin Books. 1982.

HALL Jr., R.A. Pidgins and Creoles as Standard Languages. In: PRIDE. J.B. ; HOLMES, J. (ed.) Sociolinguistcs. Selected Readings. Penguin Education, 1976.

HAUGEN, E. Dialect, Language, Nation. In: American Anthropologist, v. 68, n. 4 August. 1968. p. 922-935.

LÓPEZ EIRE, A. Del Ático a la Koiné. In: Emerita, 1981, Tomo XLIX. fasc. 2. p.173-210.

PRIDE, J.B. Sociolingüistica. In: LYONS, J. (org.). Novos Horizontes em lingüistica. São Paulo: Cultrix/EDUSP.,1976. p. 277-290.

PRIDE, J.B.; HOLMES, J. (ed.) Sociolinguistcs. Selected Readings. Penguin Education, 1976. $381 \mathrm{p}$.

RENFREW, C. Arqueologia y Lenguage.. La cuestión de los origines indoeuropeus. Barcelona: Editorial Crítica. 1990. 271 p.

ROBINS, R.H. Pequena História da Lingüistica. Rio de Janeiro: Ao Livro Técnico SA/I.N.L, 1979. 203 p.

WOLFF, H. Intelligibility and Inter-Ethnic Attitudes. In: HYMES, D. (org). Language in Culture and Society. A Reader in Linguistics and Antrhopology. Harper International Edition, 1964.

ZENGEL. M.S. Literacy as a Factor in Language Change. In: American Anthropologist. v.64, n.1. February. 1962, p.132-139. 